\title{
Pharmacological modulation of brain levels of glutamate and GABA in rats exposed to total sleep deprivation
}

This article was published in the following Dove Press journal:

Journal of Experimental Pharmacology

3 June 2010

Number of times this article has been viewed

\author{
Sahar Mohamed Kamal \\ Pharmacology Department, Faculty \\ of Medicine, Ain Shams University, \\ Cairo, Egypt
}

\begin{abstract}
Modulation of gamma-aminobutyric acid (GABA) and glutamate by selected antidepressants and anticonvulsants could play a beneficial role in total sleep deprivation (TSD) caused by depressed mood. In the present study, albino rats were exposed to TSD for five days. On the sixth day, the brains were removed, and GABA and glutamate levels were measured in the prefrontal cortex and thalamus to identify TSD-induced changes in untreated rats and in rats treated with carbamazepine $40 \mathrm{mg} / \mathrm{kg}$ intraperitoneally (IP), fluoxetine $20 \mathrm{mg} / \mathrm{kg}$ IP, or desipramine $10 \mathrm{mg} / \mathrm{kg}$ IP. Carbamazepine and fluoxetine significantly increased GABA and reduced glutamate levels in both brain areas. Desipramine administration did not affect GABA or glutamate concentrations in the tested brain areas; levels were comparable with those induced by TSD without treatment. These results suggest that administration of carbamazepine or fluoxetine could have a beneficial effect by increasing GABA levels during TSD.
\end{abstract}

Keywords: total sleep deprivation, antidepressants, carbamazepine, GABA, glutamate, rats

\section{Introduction}

Total sleep deprivation (TSD) decreases brain activity and function primarily in the thalamus, a subcortical structure involved in alertness and attention, and in the prefrontal cortex, a region regulating alertness, attention, and higher-order cognitive processes. ${ }^{1}$ TSD is clearly related to psychiatric illnesses, such as depression and phobias, and to substance addiction. ${ }^{2}$

The link between sleep deprivation and psychoses was further documented using magnetic resonance imaging scans. ${ }^{3}$ It was revealed that lack of sleep caused the brain to become incapable of putting an emotional event into the proper perspective and to be incapable of making a controlled, appropriate response to that event.

Although TSD exerts a transient beneficial effect on mood in about $60 \%$ of depressed patients, it is usually followed by a relapse into depression. ${ }^{4}$ Additionally, sleep disorders are associated with pathological changes and even death. ${ }^{5}$ The transient beneficial effect is linked to an increase in serum levels of brain-derived neurotrophic factor. ${ }^{6}$ The incidence of relapse can be decreased by combining sleep deprivation with medication. ${ }^{7}$

Glutamate and gamma-aminobutyric acid (GABA) are excitatory and inhibitory neurotransmitters, respectively, that are involved in nervous system regulation. GABA is a derivative of the amino acid, glutamic acid, and is related to the sleep-enhancing chemical, gamma-hydroxybutyrate. ${ }^{8,9}$ An increase in hypothalamic GABA levels induces sleep and $\mathrm{GABA}_{(\mathrm{A})}$ agonists help to induce sleep. ${ }^{10}$ In addition, the recent discovery that newer generations of antipsychotic drugs are neuroprotective and induce
Correspondence: Sahar Mohamed Kama Pharmacology Department, Faculty of Medicine, Ain Shams University,

Abbassia, Cairo, Egypt

$\mathrm{Tel}+20224188965$

Fax +96 6596140933

Email saharkamal2003@hotmail.com 
neurogenesis has led to exploration of the causes and potential therapies for psychotic disorders. ${ }^{11}$

The present study introduces the possibility of combining sleep deprivation and selected antidepressants (fluoxetine or desipramine) and anticonvulsants (carbamazepine) for modulation of glutamate and GABA levels in the brain to improve the consequences of TSD and depressed mood.

\section{Materials and methods Materials}

Carbamazepine, fluoxetine, and desipramine were purchased from Sigma Chemical Co. (St Louis, MO) and dissolved in deionized water. Glutamate, GABA, phenylisothiocyanate (PITC), glacial acetic acid, and L-norvaline standards were also purchased from Sigma Chemical Co. Ethanol of high-pressure liquid chromatography (HPLC) grade, triethylamine, hydrochloric acid $32 \%$, acetonitrile, and sodium acetate anhydrous were purchased from Merck (Whitehouse Station, NJ). Intraperitoneal (IP) carbamazepine $40 \mathrm{mg} / \mathrm{kg}$, fluoxetine $20 \mathrm{mg} / \mathrm{kg}$, and desipramine $10 \mathrm{mg} / \mathrm{kg}$ doses were based on previous studies. ${ }^{12,13}$ All drugs were dissolved in deionized water.

\section{Methods}

Procedures were in accordance with the Guide for the Care and Use of Laboratory Animals of the National Institutes of Health as well as the guidelines of the Animal Welfare Act. Adult male albino rats weighing $150 \mathrm{~g}$ to $175 \mathrm{~g}$ were employed throughout these studies. Rats were housed in individual cages on a 12-hour light, 12-hour dark schedule (lights on at 06:00 hours) and had access to food and water ad libitum. Experimental groups received their medications for five days and were decapitated 24 hours after the last dose.

Sleep deprivation was performed using the disc-on-water method as modified by Hsu et al. ${ }^{14}$ Briefly, the apparatus comprised two rectangular clear plastic chambers $(60 \times 20 \times 60 \mathrm{~cm}$ each $)$ placed side by side. A single plastic disc ( $40 \mathrm{~cm}$ in diameter) serving as the rat-carrying platform was built into the lower quarter of the two chambers. Beneath the disc, and extending to the chamber walls, was a rectangular tray filled with water to a depth of $5 \mathrm{~cm}$. An electric motor was set to run the rat-carrying disc at a moderate speed of $3.5 \mathrm{rpm}$ for five days; a complete cycle was defined as lasting for eight seconds with an interval of 15 seconds. Sleep deprivation depended on the rats' aversion to water; rats rarely enter water spontaneously. As sleep deprivation began, rats in the TSD group placed on the disc had to stay awake by walking against the direction of disc rotation to avoid being forced into the water. Rats in the control group (Group 1) were subjected to the same physical activity as the TSD group, with the exception that they were allowed to sleep from 06:00 to 18:00 hours when no disc movement was initiated. The sleep deprivation experiment was also approved by the Laboratory Animal Center Authorities of the Ain Shams University.

Group 1 rats $(n=12)$ served as controls, and were not exposed to TSD or treated with any drugs. Before the experiment began, animals in this group were placed in the TSD apparatus for at least seven days. For the next five days, rats were housed in the TSD apparatus but were subjected to the same physical activity as the TSD group with the exception that they were allowed to sleep from 06:00 to 18:00 hours when no disc movement was initiated. The chambers were fitted with a solid mat in place of the water. Food and water were available ad libitum throughout the entire procedure.

Before the experiment began, Group $2(\mathrm{TSD}, \mathrm{n}=12)$ animals were placed in the TSD apparatus for at least seven days. As sleep deprivation began, rats were placed on the disc and kept awake for five days by forcing them to walk against the direction of disc rotation to avoid being ejected into the water. At 8:00 hours on the sixth day, rats were sacrificed by decapitation, together with 12 control rats that received no treatment.

Group 3 rats $(n=12)$ received carbamazepine $40 \mathrm{mg} / \mathrm{kg}$ IP at 08:00 hours and were placed in the TSD apparatus for five days. Rats were subjected to the same procedure described for Group 2. The rats were sacrificed at 08:00 hours the following morning.

Groups 4 and 5 ( $\mathrm{n}=12$ rats in each group) were treated with either fluoxetine $20 \mathrm{mg} / \mathrm{kg}$ or desipramine $10 \mathrm{mg} / \mathrm{kg}$ IP for five days. Each rat was placed in the TSD apparatus for five days and subjected to the same procedure as Group 2.

\section{Anesthesia}

At 08:00 hours on the sixth day of the experiment, rats from each group were anesthetized using urethane $1 \mathrm{mg} / \mathrm{kg}$ IP and then decapitated using sharp scissors. The heads were rapidly frozen in ice. The prefrontal cortex and thalamus were rapidly dissected under cooling conditions according to previously described methods. ${ }^{15}$

\section{Determination of glutamate and GABA levels}

The glutamate and GABA levels in tissue homogenates of the prefrontal cortex and thalamus were determined according to the methods of Gunawan et al. ${ }^{16} \mathrm{HPLC}$ with precolumn PITC derivatization was used for determination of glutamate 
and GABA levels in homogenates of the prefrontal cortex and thalamus of the brains of rats from the different groups. Data are presented as nmol/mg of tissue protein.

The prefrontal cortex or thalamus from each rat was homogenized and samples were centrifuged in a cooling $\left(4^{\circ} \mathrm{C}\right)$ centrifuge at 15,000 rpm for 10 minutes. The supernatant was aspirated and transferred to an Eppendorf tube. The pellet was kept at $70^{\circ} \mathrm{C}$ until assayed for total protein content. ${ }^{16}$

Following the method of Sanacora et al, ${ }^{13}$ each sample was derivatized by drying $100 \mu \mathrm{L}$ of the aspirated supernatant in a centrivap under vacuum. The residue was dissolved in $20 \mu \mathrm{L}$ of ethanol-water-triethylamine $(2: 2: 1)$ and evaporated to dryness under vacuum. Ethanol-water-triethylamine-PITC $\mu \mathrm{L}$ (7:1:1:1) was added to the residue and allowed to react for 20 minutes at room temperature to form the PITC derivatives of the amino acids. Excess reagent was then evaporated under vacuum. The mobile phase of HPLC consisted of solvents A and $\mathrm{B}$ (solvent A: 0.1 M sodium acetate buffer $\mathrm{pH}$ 5.8; solvent B: acetonitrile:water $60: 40, \mathrm{v} / \mathrm{v}$ ). A mixture of $80 \%$ solvent $\mathrm{A}$ and $20 \%$ solvent B was adjusted for the "isocratic" HPLC separations. Flow rate was set at $0.6 \mathrm{~mL} / \mathrm{min}$. The injected sample was $20 \mu \mathrm{L}$. The peaks were detected at a $254 \mathrm{~nm}$ wavelength. Standard curves for glutamate or GABA and norvaline were plotted using norvaline $2 \mathrm{nmol} / 20 \mu \mathrm{L}$ as an internal standard. The ratio of the peak area of each concentration of the standard to the peak area of the internal standard was determined and entered against the concentration of the standard in a simple regression procedure.

\section{Quantification of total tissue protein}

Total protein was measured according to the method of Bradford. ${ }^{17}$ The aim of this procedure was to correlate glutamate and GABA concentrations to the amount of total tissue protein.

\section{Analysis of the data}

The data obtained are presented as mean \pm standard error of measurement (SEM) and were evaluated using one-way ANOVA, followed by Bonferroni's post hoc determination, using GraphPad Prism version 3.00 for Windows 97 (Graph Pad Software, San Diego, CA).

\section{Results}

\section{Drug effects on glutamate levels in the prefrontal cortex of rats exposed to TSD}

Figure 1 shows the changes in glutamate concentration in the prefrontal cortex of the control, TSD, and TSD + carbamazepine-, fluoxetine-, and desipramine-treated rats.

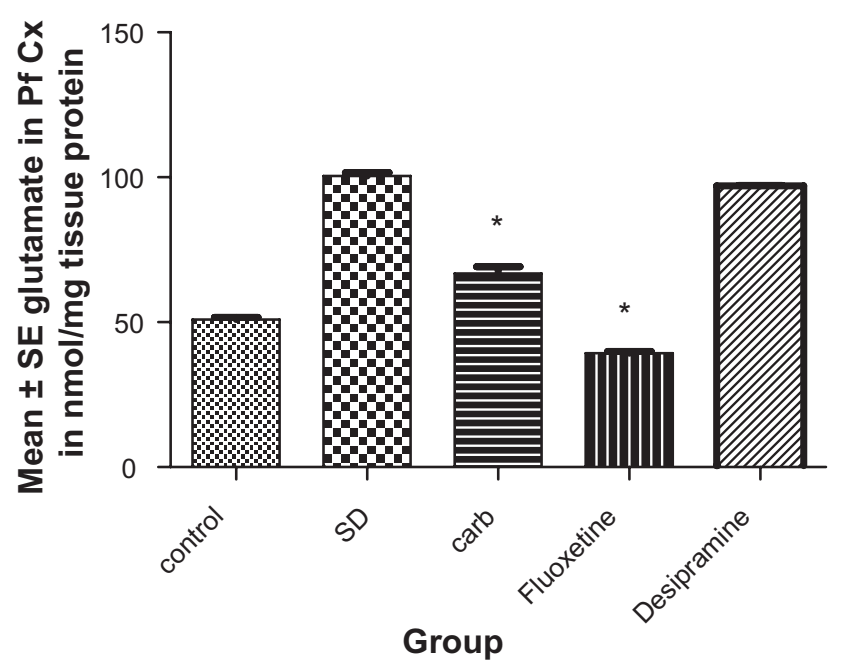

Figure I Influence of TSD on glutamate in Pf.Cx of male albino rats of the different groups; control deionized water-treated as well as TSD with and without carbamazepine, fluoxetine, and desipramine treatment. Data are expressed as the mean \pm SEM from 12 animals per group.

Note: $P<0.05$ significant reduction versus TSD group without treatment.

Abbreviations: Pf.Cx, prefrontal cortex; TSD, total sleep deprivation; SEM, standard error of measurement.

TSD significantly increased $(P<0.05)$ glutamate concentration in the prefrontal cortex $(50.92 \pm 0.74 \mathrm{nmol} / \mathrm{mg}$ tissue protein in the control group versus $100.4 \pm 1.10 \mathrm{nmol} / \mathrm{mg}$ tissue protein in the TSD group without treatment).

Glutamate concentration was reduced significantly $(P<0.05)$ by carbamazepine administration $(66.83 \pm 2.41 \mathrm{nmol} / \mathrm{mg}$ tissue protein in controls versus $100.4 \pm 1.10$ for the TSD group without treatment).

Glutamate concentration was decreased significantly $(P<0.05)$ by fluoxetine. Administration of desipramine did not alter the glutamate level in TSD rats, which was comparable with glutamate levels induced by TSD without treatment $(39.25 \pm 0.66$ and $97 \pm 0.23 \mathrm{nmol} / \mathrm{mg}$ tissue protein for fluoxetine and desipramine, respectively, versus $100.4 \pm 1.1 \mathrm{nmol} / \mathrm{mg}$ tissue protein for the TSD group without treatment).

\section{Drug effects on GABA levels in prefrontal cortex of rats exposed to TSD}

Changes in GABA concentration in the prefrontal cortex of the control, TSD, and TSD + carbamazepine-, fluoxetine-, and desipramine-treated rats are demonstrated in Figure 2. TSD significantly decreased $(P<0.05)$ the GABA concentration in the prefrontal cortex $(48.75 \pm 0.33 \mathrm{nmol} / \mathrm{mg}$ tissue protein versus $129.6 \pm 0.42 \mathrm{nmol} / \mathrm{mg}$ tissue protein for the control group). GABA concentration was increased significantly $(P<0.05)$ by carbamazepine treatment $(100.2 \pm 0.30 \mathrm{nmol} / \mathrm{mg}$ tissue protein) compared with the 


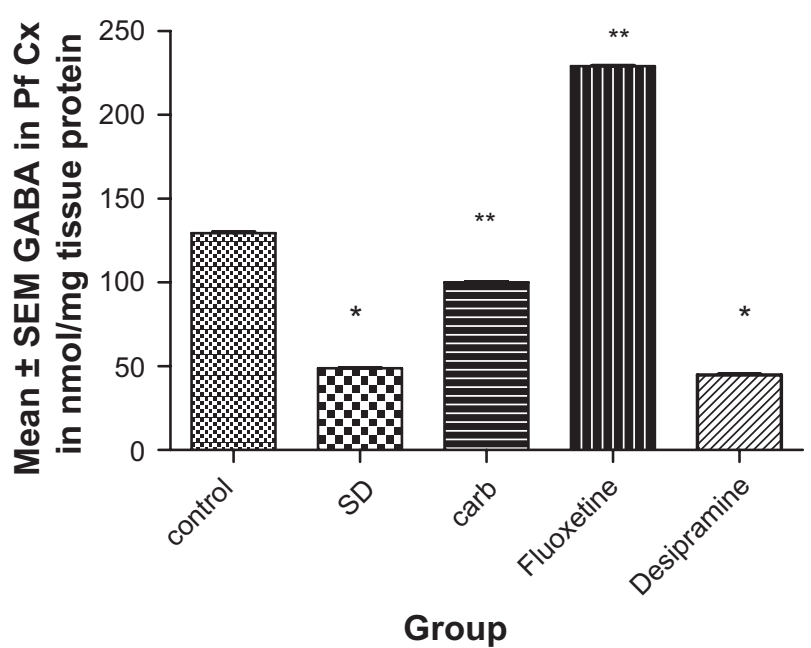

Figure 2 Influence of TSD on GABA in Pf.Cx of male albino rats of the different groups:control deionized water-treated;as well as TSD with and without carbamazepine, fluoxetine, and desipramine treatment. Data are expressed as the mean \pm SEM from 12 animals per group.

Note: ${ }^{*} P<0.05$ significant decrease versus control. ${ }^{* *} P<0.05$ significant increase versus TSD group without treatment.

Abbreviations: Pf.Cx, prefrontal cortex; TSD, total sleep deprivation; SEM, standard error of mean; GABA gamma-aminobutyric acid.

TSD group without treatment. The GABA concentration in rats was increased significantly $(P<0.05)$ by fluoxetine treatment. Administration of desipramine did not increase GABA levels in TSD rats; GABA concentrations were comparable with those induced by TSD without treatment $(229.1 \pm 0.37$ and $44.92 \pm 0.32 \mathrm{nmol} / \mathrm{mg}$ tissue protein of fluoxetine and desipramine, respectively, versus $48.75 \pm 0.33$ for the TSD group without treatment).

\section{Drug effects on glutamate levels in the thalamus of rats exposed to TSD}

Changes in glutamate concentration in the thalamus of the control, TSD, and TSD + carbamazepine-, fluoxetine-, and desipramine-treated rats are shown in Figure 3.

TSD significantly $(P<0.05)$ increased the glutamate concentration in the thalamus compared with that in the control group $(100 \pm 5.5 \mathrm{nmol} / \mathrm{mg}$ tissue protein versus $35 \pm 2.4 \mathrm{nmol} / \mathrm{mg}$ tissue protein for the control group).

Glutamate concentration was not altered by carbamazepine treatment compared with the TSD group $(99.79 \pm 1.21 \mathrm{nmol} / \mathrm{mg}$ tissue protein for carbamazepine treatment versus $100 \pm 5.5 \mathrm{nmol} / \mathrm{mg}$ tissue protein for the TSD group without treatment).

Glutamate concentration was reduced significantly $(P<0.05)$ by fluoxetine treatment compared with TSD without treatment. Administration of desipramine did not alter glutamate levels in TSD rats; glutamate concentrations were comparable with those induced by TSD without treatment $(40.21 \pm 1.19$

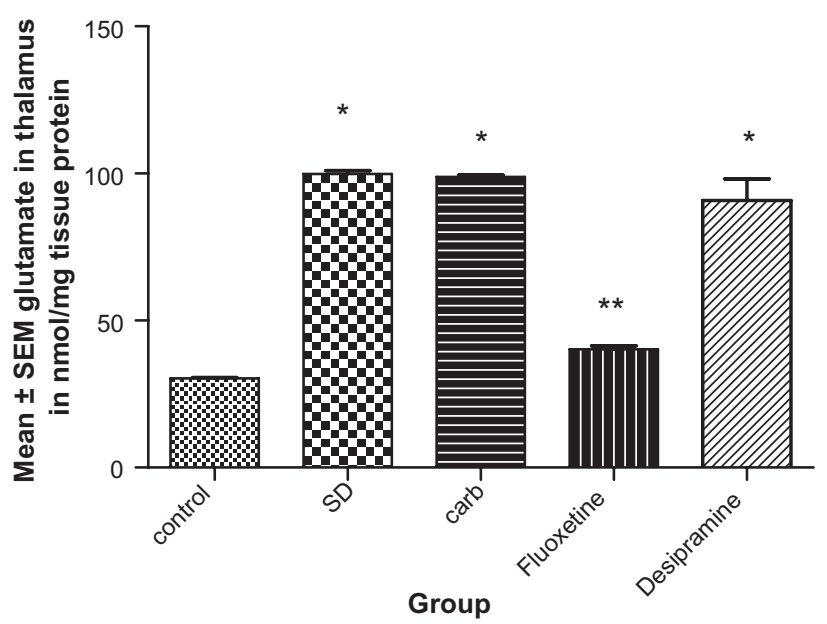

Figure 3 Influence of TSD on glutamate in thalamus of male albino rats of the different groups: control deionized water-treated as well as TSD with and without carbamazepine, fluoxetine, and desipramine treatment. Data are expressed as the mean \pm SEM from 12 animals per group.

Note: ${ }^{*} P<0.05$ significant increase vsersus control. ${ }^{\text {*k* }} P<0.05$ significant reduction versus TSD group without treatment.

Abbreviations: TSD, total sleep deprivation; SEM, standard error of mean.

and $90.75 \pm 7.48 \mathrm{nmol} / \mathrm{mg}$ tissue protein for fluoxetine and desipramine, respectively, versus $100 \pm 5.5 \mathrm{nmol} / \mathrm{mg}$ tissue protein for the TSD group without treatment).

\section{Drug effects on GABA levels in the thalamus of rats exposed to TSD}

Alterations in GABA concentration in the thalamus of the control, TSD, and TSD + carbamazepine-, fluoxetine- and desipramine-treated rats are presented in Figure 4.

TSD significantly $(P<0.05)$ decreased the GABA concentration in the thalamus. GABA concentration was significantly $(P<0.001)$ increased by carbamazepine treatment $(50 \pm 0.17 \mathrm{nmol} / \mathrm{mg}$ tissue protein in TSD + carbamazepine-treated rats versus $20 \pm 0.27 \mathrm{nmol} / \mathrm{mg}$ tissue protein for the TSD group without treatment).

GABA concentration was significantly $(P<0.05)$ increased by fluoxetine treatment. Administration of desipramine did not increase GABA levels in TSD rats; GABA concentrations were comparable with those induced by TSD without treatment $(120 \pm 0.47$ and $14.88 \pm 0.14 \mathrm{nmol} / \mathrm{mg}$ tissue protein for fluoxetine and desipramine, respectively, versus $20 \pm 0.27 \mathrm{nmol} / \mathrm{mg}$ tissue protein for the TSD group without treatment).

\section{Discussion}

In the present study, exposure of rats to five days of TSD was associated with a significant increase in glutamate and a significant decrease in GABA concentrations in the prefrontal cortex or thalamus. These changes were reversed 


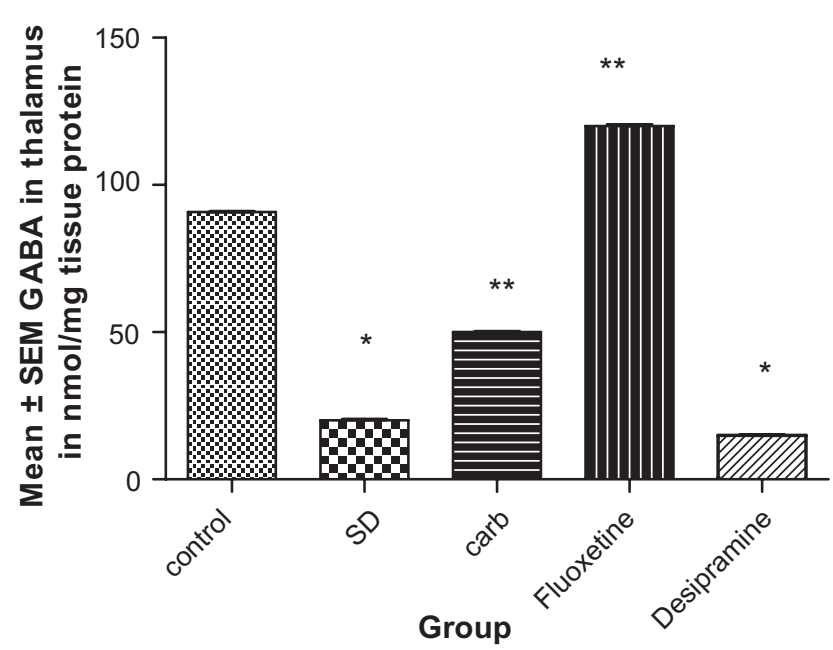

Figure 4 Influence of TSD on GABA in thalamus of male albino rats of the different groups: control deionized water-treated as well as TSD with and without carbamazepine, fluoxetine, and desipramine treatment. Data are expressed as the mean \pm SEM from 12 animals per group.

Note: $P<0.05$ significant decrease versus control. ${ }^{* *} P<0.05$ significant increase versus TSD group without treatment.

Abbreviations: TSD, total sleep deprivation; SEM, standard error of mean; GABA gamma aminobutyric acid.

to levels comparable with those in control rats by administration of carbamazepine, an antiepileptic drug, and fluoxetine, a selective serotonin reuptake inhibitor. However, altered levels of glutamate persisted in the thalamus with carbamazepine administration. Desipramine, a norepinephrine reuptake inhibitor, did not alter either glutamate or GABA concentrations.

In a previous pilot study, TSD for more than five days resulted in death of experimental albino rats. However, significant changes in both GABA and glutamate levels were reported after the first 24 hours of TSD. These changes were maintained over the five days of TSD until their death. So the present study was conducted for five days of TSD with and without concomitant administration of the tested drugs to determine any possible alteration induced by these drugs during the survival period on the already reported changes in neurotransmitter levels.

Thalamocortical networks generate specific patterns of oscillations controlled by GABAergic transmission to regulate normal sleep homeostasis. ${ }^{18}$ GABA, derived from glutamate, plays a role in arousal via its inhibitory effect on the basal forebrain tract, and plays a role in sleep by increasing GABA levels in the hypothalamus. ${ }^{18}$ GABA release in the posterior hypothalamus mediates inhibition of posterior hypothalamic neurons, thereby facilitating sleep..$^{19}$ Altered GABA concentration in either the prefrontal cortex or thalamus is associated with sleep deprivation in rats. ${ }^{11}$
The increase in glutamate level in the tested brain areas is consistent with the findings of Bettendorff et $\mathrm{al}^{20}$ who observed that paradoxical sleep deprivation increased the content of glutamate and glutamine in the rat cerebral cortex. These findings suggest that increased levels of glutamate may override any direct enhancing effects of GABA on neurons during TSD. Additionally, sleep deprivation was associated with a significant increase in glutamate levels in the hippocampus and thalamus.

The effect of carbamazepine on GABA levels may be attributed to GABAergic and antiglutamatergic activity. ${ }^{21}$ Additionally, preclinical studies show that carbamazepine induces a decreased GABA turnover in animals.22

Oral fluoxetine administration to Sprague Dawley rats $(5 \mathrm{mg} / \mathrm{kg}$ ) for 21 days elevates GABA cerebrospinal fluid levels by approximately twofold. This neurochemical finding shows that fluoxetine affects brain GABA levels. ${ }^{6}$ However, fluoxetine is not directly GABAergic and may indirectly enhance GABAergic neurotransmission. Patients with major depressive disorder (unipolar)who received fluoxetine showed an increase in occipital GABA concentrations, ${ }^{23}$ and normalization of cerebral GABA deficiency. ${ }^{24}$ This effect could be related to selective serotoin reuptake inhibitor-induced increases in brain allopregnanolone, a GABAergic neurosteroid that binds with high affinity to various $\mathrm{GABA}_{\mathrm{A}}$ receptor subtypes, potentially facilitating GABAergic actions. ${ }^{18}$ These results could explain the increase in GABA levels reported in the brain areas investigated in the present study.

In rats not previously exposed to a model of depression, chronic administration of desipramine increased frontal $\mathrm{GABA}_{\mathrm{B}}$, but not $\mathrm{GABA}_{\mathrm{A}}$, receptors. ${ }^{25}$ The upregulation of $\mathrm{GABA}_{\mathrm{B}}$ receptors could be due to the decreased GABA concentration associated with desipramine administration. This consideration was excluded from the work of Rechtschaffen et al, ${ }^{5}$ which supported the lack of effect of desipramine on GABA reported by the present study.

The interaction between the administration of the serotonergic antidepressant compound fluoxetine and repeated cycles of TSD was tested in bipolar depressed patients. Patients treated with fluoxetine plus repeated TSD showed a faster amelioration of depressive symptomatology compared with the nontreated group exposed only to repeated cycles of TSD. The authors hypothesized that enhanced dopaminergic and serotonergic transmission due to repeated TSD might add to the increase in serotonergic transmission generated by fluoxetine medication. ${ }^{26}$

Indeed, TSD has been used in association with lithium salts and with serotonergic and noradrenergic 
antidepressants, leading to sustained improvements in patients affected by major depression, ${ }^{27}$ and suggesting the utility of combining TSD with antidepressants. The clinical efficacy of this procedure used alone is limited by the waning of improvement during the next night of sleep, ${ }^{28}$ an effect most probably related to changes in brain neurotransmitters that play a crucial role in sleep mechanisms. Therefore, if TSD is supported by a proper drug regimen, a beneficial effect may be achieved.

The present study reported no alteration by desipramine of the levels of either glutamate or GABA in homogenates of the tested brain structures. A clinical study reported no changes in plasma GABA after four weeks of treatment with desipramine in patients with major depression. ${ }^{29}$ Desipramine increased extracellular norepinephrine that may augment release of GABA in different brain areas. However, studies reported that norepinephrine concentration was lower in the neocortex, hippocampus, and posterior hypothalamus in rats exposed to sleep deprivation compared with control rats, together with an increase in expression of tyrosine hydroxylase enzyme in these areas as a mechanism for adjustment to TSD. This low availability of norepinephrine in such areas could hinder any possible changes by desipramine on GABA levels in this animal model. ${ }^{30}$

This study concludes that carbamazepine and fluoxetine exerted a GABAergic action when administered during total sleep deprivation. Therefore, these compounds may play a useful role in the strategic plan of treatment for TSD.

\section{Acknowledgment}

This research was supported by the Medical Research Service of the Ain Shams University, Cairo, Egypt. It was supported by the HPLC Laboratory of the Pharmacology Department, Faculty of Medicine, Ain Shams University, Cairo, Egypt.

\section{Disclosure}

The author reports no conflict of interest in this work.

\section{References}

1. Uzunova V, Sheline Y, Davis JM. Increase in the cerebrospinal fluid content of neurosteroids in patients with unipolar major depression who are receiving fluoxetine or fluvoxamine. Proc Natl Acad Sci U SA. 1998;95(6):3239-3244

2. Kimber JR, Cross JA, Horton RW. Benzodiazepine and GABAA receptors in rat brain following chronic antidepressant drug administration. Biochem Pharmacol. 1987;36(23):4173-4175.

3. Goes F, Zandi P, Miao K. Mood-incongruent psychotic features in bipolar disorder: Familial aggregation and suggestive linkage to 2p11-q14 and 13q21-33. Am J Psychiatry. 2007;164(2): 236-247.

4. Holsboer-Trachsler E, Seifritz E. Sleep in depression and sleep deprivation: A brief conceptual review. World J Biol Psychiatry. 2000; 1(4):180-186.
5. Rechtschaffen A, Siegel JM. Sleep and dreaming. In: Kandell ER, Schwartz JH, Jessel TM, editors. Principles of Neuroscience. New York, NY: McGraw-Hill; 2000.

6. Gören MZ, Küçükibrahimoglu E, Berkman K, Terzioglu B. Fluoxetine partly exerts its actions through GABA: A neurochemical evidence. Neurochem Res. 2007;32(9):1559-1565.

7. Wirz-Justice A, Van den Hoofdakker R. Sleep deprivation in depression: What do we know, where do we go? Biol Psychiatry. 1999;46(4): $445-453$.

8. Lloyd KG, Thuret F, Pilc A. GABA and the mechanism of action of antidepressant drugs. In: Bartholini G, Lloyd KG, Morselli PL, editors. GABA and Mood Disorders: Experimental and Clinical Research. New York, NY: Raven Press; 1986.

9. Zhong P, Yan Z. Chronic antidepressant treatment alters serotonergic regulation of GABA transmission in prefrontal cortical pyramidal neurons. Neuroscience. 2004;129(1):65-73.

10. Harrison NL. Mechanisms of sleep induction by GABA(A) receptor agonists. J Clin Psychiatry. 2007;68 Suppl 5:6-12.

11. Wang H, Dunnavant F, Jarman R. Effects of antipsychotic drugs on neurogenesis in the forebrain of adult rat. Neuropharmacology. 2004;29(7):1230-1238.

12. Eravci M, Pinna G, Meinhold H, Baumgartner A. Effects of pharmacological and nonpharmacological treatments on thyroid hormone metabolism and concentrations in rat brain. Endocrinology. 2000;141(3):1027-1040.

13. Sanacora G, Mason GF, Rothman DL. Increased occipital cortex GABA concentrations in depressed patients after therapy with selective serotonin reuptake inhibitors. Am J Psychiatry. 2002;159(4):663-665.

14. Hsu JC, Lee YS, Chang CN, Chuang HL, Ling EA, Lan CT. Sleep deprivation inhibits expression of NADPH-d and NOS while activating microglia and astroglia in the rat hippocampus. Cells Tissues Organs. 2003;173(4):242-254.

15. Glowinski I, Iversen L. Regional studies of catecholamine metabolism in the rat brain. I. The disposition of $(3 \mathrm{H})$ dopamine and $(3 \mathrm{H})$ dopa in various regions of the brain. J Neurochem. 1966;13(8):655-669.

16. Gunawan S, Walton N, Treiman D. High performance liquid chromatography determination of selected amino acids in rat brain by precolumn derivatization with phenylisothiocyanate. J Chromatogr. 1990;503(1):177-187.

17. Bradford M. A rapid and sensitive method for the quantitation of microgram quantities of protein utilizing the principle of protein-dye binding. Anal Biochem. 1976;72:248-254.

18. Winsky-Sommerer R, Knapman A, Fedele D, et al. Normal sleep homeostasis and lack of epilepsy phenotype in GABA A receptor alpha3 subunit-knockout mice. Neuroscience.2008;154(2):595-605.

19. Nitz D, Siegel J. GABA release in posterior hypothalamus across sleepwake cycle. Am J Physiol. 1996;271:R1707-R1712.

20. Bettendorff L, Sallanon-Moulin M, Touret M, Wins P, Margineanu I, Schoffeniels E. Paradoxical sleep deprivation increases the content of glutamate and glutamine in rat cerebral cortex. Sleep. 1996; 19(1):65-71.

21. Pratt GD, Bowery NG. Repeated administration of desipramine and a GABAB receptor antagonist, CGP 36742, discretely up-regulates GABAB receptor binding sites in rat frontal cortex. Br J Pharmacol. 1993;110(2):724-735.

22. Thomas M, Sing H, Belenky G, et al. Neural basis of alertness and cognitive performance impairments during sleepiness. J Sleep Res. 2000;9(4):335-352.

23. Schwark WS, Loscher W. Comparison of the anticonvulsant effects of two novel GABA uptake inhibitors and diazepam in amygdaloid kindled rats. Naunyn Schmiedebergs Arch Pharmacol. 1985;329(4):367-371.

24. Sanacora G, Mason GF, Rothman DL, Krystal JH. Reduced cortical gamma-aminobutyric acid levels in depressed patients determined by proton magnetic resonance spectroscopy. Arch Gen Psychiatry. 1999;56(11):1043-1047.

25. Motohashi N. GABA receptor alterations after chronic lithium: In comparison with carbamazepine and sodium valproate. Prog Neuropsychopharmacol Biol Psychiatry. 1992;16(4):571-579. 
26. Benedetti F, Campori E, Barbini B, Fulgosi MC, Colombo C. Dopaminergic augmentation of sleep deprivation effects in bipolar depression. Psychiatry Res. 2001;104(3):239-246.

27. Benedetti F, Barbini B, Lucca A, Campori E, Colombo C, Smeraldi E. Sleep deprivation hastens the antidepressant action of fluoxetine. Eur Arch Psychiatry Clin Neurosci. 1997;247(2):100-103.

28. Riemann D, Konig A, Hohagen F, et al. How to preserve the antidepressive effect of sleep deprivation: A comparison of sleep phase advance and sleep phase delay. Eur Arch Psychiatry Clin Neurosci. 1999;249(5):231-237.
29. Petty F, Steinberg J, Kramer G, Fulton M, Moeller G. Desipramine does not alter plasma GABA in patients with major depression. JAffect Disord. 1993;29(1):53-55.

30. Gottesmann C. Noradrenaline involvement in basic and higher integrated REM sleep processes. Prog Neurobiol. 2008;85(3):237-272.

\section{Publish your work in this journal}

The Journal of Experimental Pharmacology is an international, peerreviewed, open access journal publishing original research, reports, reviews and commentaries on all areas of laboratory and experimenta pharmacology. The manuscript management system is completely online and includes a very quick and fair peer-review system.

\section{Dovepress}

Visit http://www.dovepress.com/testimonials.php to read real quotes from published authors. 